\title{
Analyzing the Impact of One Important Unplanned Exceptional Event, Hurricanes, on Crime in Louisiana, U.S. Using a Visual Analytics Approach
}

\author{
Michael LEITNER ${ }^{1}$ and Diansheng GUO ${ }^{2}$ \\ ${ }^{1}$ Louisiana State University, Baton Rouge/USA · mleitne@1su.edu \\ ${ }^{2}$ University of South Carolina, Columbia/USA
}

This contribution was double-blind reviewed as full paper.

\begin{abstract}
This research is a follow-up study of LEITNER et al. (2011) who assessed the effect that one natural disaster - Hurricane Katrina - and subsequent population movements have had on crime in the state of Louisiana, U.S. Instead of using autoregressive, integrated, and moving average (ARIMA) models and cumulative percentile maps to analyze spatial and temporal trends of crimes across the study area, this study utilizes a visual analytics approach that integrates self-organizing map, color encoding, and multidimensional visualization. Such an approach is especially useful for the analysis of complex datasets that contain geographic locations, time series, and multiple variables.
\end{abstract}

\section{Introduction and Literature Review}

This paper constitutes a status report on an ongoing larger research project trying to answer the question how exceptional events, unplanned or planned, impact the spatial and temporal distribution of crime. In this context, unplanned exceptional events are defined as "any occurrence that causes damage, ecological disruption, loss of human life or deterioration of health and human services". Such events can happen suddenly, are often unpredictable, and allow little or no time for warning and preparation. They include any type of disasters, be it natural (hurricanes, tornadoes, earthquakes, fires, floods, ice-storms, etc.) or manmade (9/11, oil spill, nuclear accident, blackouts, etc.).

Planned exceptional events are usually associated with the gathering of large amount of people in a confined geographic area over some period of time. Such events are usually known months or even years in advance. Examples of planned exceptional events include any types of sporting events (Soccer World Cup, Olympic Games, World Series, Super Bowl, America's Cup, etc.), music festivals (Woodstock, New Orleans Jazz \& Heritage Festival, etc.), parades (Mardi Gras, Thanksgiving Day Parade, Love Parade, etc.), political, governmental, or international meetings (Democratic/Republican National Convention, World Economic Forum, G20 Summit, International AIDS Conference, etc.), or demonstrations (Occupy Wall Street, Arab Spring, etc.). 
Whether planned or unplanned, exceptional events affect lifestyles and the routines of large amount of people (ANDRESEN \& TONG 2012). Exceptional events can have huge positive or negative economic impacts for the affected area. While the National Football League's final game, the Super Bowl, can generate more than half a billion US\$ (O'GRADY 2011), large hurricanes can create tens of billions US\$ in damage and even human fatalities. While the economic impact is usually studied in detail, surprisingly little is known about the impact that exceptional events have on crime. Among the existing literature of unplanned exceptional events, hurricanes are usually the ones that have been discussed the most. Examples include Hurricane Andrew (CROMWELL et al. 1995, LANZA-KADUCE et al. 1998), Hurricane Hugo (LeBeAu 2002), Hurricane Katrina (BAILEy 2009, LeITNER et al. 2011), and both Hurricanes Katrina and Rita (LAWTON \& SchulenBURG 2007, LeITNER \& HelBich 2011).

The focus in this study is on the relationship between one particular type of an unplanned exceptional event, namely hurricanes, and crime. Specifically, this research uses different spatial and temporal visual approaches to explore the impact that Hurricanes Katrina and Rita have on the spatial and temporal distribution of eight different crime types, including murder, rape, robbery, aggravated assault, simple assault, burglary, larceny theft, and motor vehicle theft.

Among the theories that can be used to explain the effect that natural disasters have on crime is the routine activity theory (COHEN \& FELSON 1979). According to this theory, crime happens at the convergence in space and time of motivated offenders, suitable targets, and the absence of capable guardians against violation. Changes to this routine activity pattern and thus changes to the number of crimes being committed could be triggered by natural disasters, among other things. For example, disaster areas could see fewer motivated offenders and targets, as many of them have already evacuated and there is often an increase in capable guardians. This would point to a possible decrease in crime in areas hardest hit by a disaster, until normalcy returns. On the other hand, host regions for disaster evacuees could see an increase in motivated offenders and suitable targets and a relative decrease in capable guardians for at least the short term. This would point to a possible (short term) increase in crime in the evacuation areas. Similarly, social strain theory (AGNEW 2005) and social disorganization theory (SAMPSON \& GROVES 1989) would also see an increase in crime in evacuation areas by arguing that the introduction of a large and often highly visible disadvantaged population would likely worsen crime rates within a specific jurisdiction. Furthermore, isolation from both traditional social services and the influence of positive community-based institutions (i.e., schools, churches, and neighbor advocacy groups) might further exasperate conditions in which social disorder would thrive (LEITNER et al. 2011).

Communities directly affected by disasters undergo a cyclical process of four overlapping stages that include mitigation, preparedness and planning, emergency and recovery, and reconstruction. The first two stages take place before and the final two stages take place after the disaster. It is believed that crime remains unaffected during the first two stages, unless a mandatory evacuation order due to the threat of an approaching hurricane calls for citizens to leave their residences. It is further believed that crime generally trends downward during the recovery stage and gradually returns to pre-disaster levels during the reconstruction stage. The downward trend during the recovery stage is due in part to emergent prosocial behaviors that create an atmosphere of altruism among the members of the community (DRABEK \& MCENTIRE 2003). CROMWELL et al. (1995) referred to this behav- 
ior as informal guardianship. After some time, the altruism of the community fades away and crime returns to predisaster levels (BAILEY 2009).

Two very recent studies have investigated whether (mandatory) mass evacuations in the wake of an approaching hurricane would have an effect on crime (LAWTON \& SCHULENBURG 2007; LEITNER \& HELBICH 2011). Such evacuations would obviously take place before the hurricane's landfall during the planning stage. Both studies found that during the 2005 hurricane season, Houston witnessed a significant increase in burglaries and a minor spike for auto thefts concurrent with the largest ever mandatory evacuation in the city's history due to the approaching Hurricane Rita. The increase in the number of auto thefts was shorter and less pronounced. All other crime types showed a slight decrease during the evacuation period for Hurricane Rita in Houston (LAWTON \& SCHULENBURG 2007; LEITNER \& HELBICH 2011).

The belief that crime rates trend downwards during the recovery stage following a disaster has been supported by some empirical studies (SUAR \& KAR 2005; CROMWELL et al. 1995). However, other empirical studies did not find any statistically significant differences during the emergency stage as compared to an average period before the hurricane (WENGER \& FRIEDMAN 1986). In contrast, FRAILING and HARPER (2007) found that burglary rates in New Orleans for three different hurricanes - one being Hurricane Katrina - increased up to fourfold (in the case of Katrina) in the month following a disaster as compared to the one month prior to a disaster. Similarly, MuNASINGHE (2007) found that robberies of valuable items and simple looting of supplies prevailed in New Orleans during the emergency stage of Hurricane Katrina.

The belief that crime rates gradually return to predisaster levels during the reconstruction stage was empirically tested by just a few studies. The results from these studies are somewhat inconclusive. For example, in a study of six different crime types in New Orleans following Hurricane Katrina, BAILEY (2009) found that robbery, burglary, and larceny rates returned to pre-Katrina levels by December 2007. In contrast, murder and aggravated assault rates remained significantly higher than pre-Katrina averages, whereas motor vehicle theft rates remained below prestorm levels by the end of 2007 . VANLANDingham $(2007 ; 2008)$ confirmed the results from BAILEY (2009) and found that the 2006 and 2007 murder rates in New Orleans after Hurricane Katrina exceeded preKatrina levels.

One of the few empirical studies that investigated whether crime changed in those places that accepted evacuees from impacted areas used time series analysis, specifically autoregressive, integrated, and moving average (ARIMA) models (LEITNER et al. 2011). Results showed that violent and nonviolent crime rates remained unchanged following Hurricane Katrina. Specifically, fourteen of the sixty-four parishes analyzed showed a (statistically) significantly stronger decrease in violent crime rates after August 2005, whereas eleven parishes had a significantly stronger decrease in nonviolent crime rates in the posthurricane period.

To sum up, empirical evidence does not necessarily support the theories trying to explain the effect that natural disasters have on crime. Empirical study outcomes seem to vary across the cultural context in which the study takes place, the type of crime being investigated, the severity of the disaster, and not surprisingly, the quality (foremost completeness) of the crime data being collected. 


\section{Data and Study Area}

This research is based upon a portion of a much larger crime data set that includes the socalled Part I offenses as defined by the Federal Bureau of Investigation (FBI 2007) Uniform Crime Report (UCR) program. The eight Part 1 offenses are murder, rape, robbery, aggravated assault, simple assault, burglary, larceny theft, and motor vehicle theft. The unit of observation is the Louisiana parish - there are sixty-four parishes in the state - and the time period is from January 12005 until December 31 2005, selected from a data set that includes the same offenses over an entire eleven year period (January 12000 - December 31 2010). The longitudinal analysis in this research thus captures the year in which Hurricanes Katrina and Rita made landfall at or close to the Louisiana coastline on August 292005 (Hurricane Katrina) and on September 242005 (Hurricane Rita), respectively.

Crime statistics were acquired through a cooperative with the Louisiana Commission on Law Enforcement (LCLE), which serves as the state's coordinating body for the Louisiana Uniform Crime Report (LA UCR) program. The LCLE is also the certified contributor to the UCR program maintained by the FBI. The LA UCR program collects crime data from the law enforcement agencies within each of the state's sixty-four parishes and forwards them to the FBI. The original larger crime data set collected from the LCLE included monthly crime totals that were reported for all individual enforcement agencies within all 64 parishes between 2000 and 2010. These agencies include the parish sheriff, municipal police departments, universities, and medical institutions (LCLE 2007). Overall, the average number of agencies per parish declined from three in 2000 to two and one-half in 2005 (LEITNER et al. 2011). The number of agencies is usually higher in urban parishes and lower in rural parishes.

All eight Part I offenses were summed up for all individual enforcement agencies in each parish and for each month resulting in a matrix of eight individual crime types (multivariate dimension), 64 parishes (spatial dimension), and twelve months (temporal dimension). This data set consisting of 6,144 values constituted the input file for VIS-STAMP.

\section{$3 \quad$ Analysis and Results}

VIS-STAMP, an acronym for Visualization for Space Time and Multivariate Patterns, is a visual analytics approach to the analysis of complex datasets that contain geographic locations, time series, and multiple variables (GUO et al., 2006). The VIS-STAMP software can be downloaded for free from http://spatialdatamining.org/software/visstamp. It integrates a self-organizing map (a dimension reduction and clustering method, SOM), color encoding, and multidimensional visualization to map the changing trends and relationships of multiple variables over space and time.

To answer our specific research question, namely the effect that Hurricanes Katrina and Rita had on crime across Louisiana at the parish level and for each month in 2005, this study replicates a similar study done by GUO and WU (2013), who analyzed crime data in Philadelphia, PA from January 2007 to June 2011. The general question that we want to answer is: How do temporal trends differ in different places and for different crime types. For example, one type of crime may have been increasing while another type(s) of crime(s) 
may have been declining for some parishes in Louisiana. For this purpose, VIS-STAMPS divides the number of offenses for each crime type in each parish and month by the total number of offenses in each parish and month. In other words, the (original) crime counts for each crime type are changed to percentages, representing the proportion of a specific crime type against the total number of crimes for a parish in a particular month. For example, Parish A had 100 robbery crimes out of a total of 1,000 crimes that happened in that parish in time period T1 then $10 \%$ of all crimes can be attributed to robberies in Parish A during time period $\mathrm{T} 1$.

After a preliminary analysis of the original data set, we decided to cut down the number of crime types to five, including robbery, aggravated assault, burglary, larceny theft, and motor vehicle theft. We eliminated rape, murder, and simple assault from the subsequent analysis mostly for two reasons. First, the counts for rape and murder were rather low and resulted in small percentages compared to the other five crime types. Their trends are thus less stable due to their small sampling sizes. Consequently, if included, they would have diluted the patterns of the other crimes. Second, simple assault seemed to us as having a less obvious trend and when included, it would have also diluted the patterns of the other five crime types. However, the percentage values of the five crime types are against the total of all eight crime types. This means that in some sense, those three excluded crime types are considered to a certain degree in the calculation of the percentages of the crime types selected for further analysis.

In a first step we applied VIS-STAMP to create a SOM to cluster crime compositions, each of which is for a specific parish and month combination (figure 1 bottom). More importantly, the SOM orders clusters (nodes) in a two-dimensional layout so that nearby clusters (nodes) are similar in terms of crime compositions. The SOM was configured to be $7 \times 7$ resulting in 49 clusters (figure 1 bottom). The SOM size is a compromise between accuracy (more nodes result in a higher accuracy) and the ability to display each node with an individual color that is distinguishable in maps and graphical displays. For example, a larger SOM size, say $11 \times 11$ cannot be used, due to the difficulty to display 121 different clusters with 121 different colors. Also, a smaller size, say 5x5 would not significantly change the results, since the SOM produces a surface. With SOM, the most similar data objects are placed in the same cluster with similar clusters being located next to each other in the 2D layout of SOM clusters (figure 1 bottom). We then used a systematically designed two-dimensional color scheme to assign a color to each SOM cluster (node) so that similar clusters have similar colors. Thus, the method effectively transforms the multivariate data (i.e., crime compositions) into a color space, which can assist visual perception of crime patterns across space and time. Readers are referred to GUO et al. (2006) for more technical details of this methodology. The color of each cluster now represents the multivariate mean vector of the cluster. The meaning of the color (and the cluster it represents) can be interpreted from a linked parallel coordinate plot (PCP), in which each line represents a cluster, with the same color as it has in the SOM (figure 1 top).

In a second step, we created a matrix of twelve maps, each of which is representing the spatial distribution of five crime types (whose particular composition is represented by a color that was assigned in the resulting SOM) for each month in 2005 (figure 2). If a parish had less than ten crimes in total for a specific month, its crime data for that month was excluded from the analysis and visualized in a gray color on the map. The main reason is that this very low crime total resulted in a rather unstable composition (percentages) of 
different crime types. In other words, in order to reliably compare different compositions, sufficiently larger sample sizes are needed. A value of 10 may be still on the low end of a sufficiently large enough sample, size. Altogether, only less than 20 out of a total number of 768 (64 parishes x 12 months) parish-months were removed.
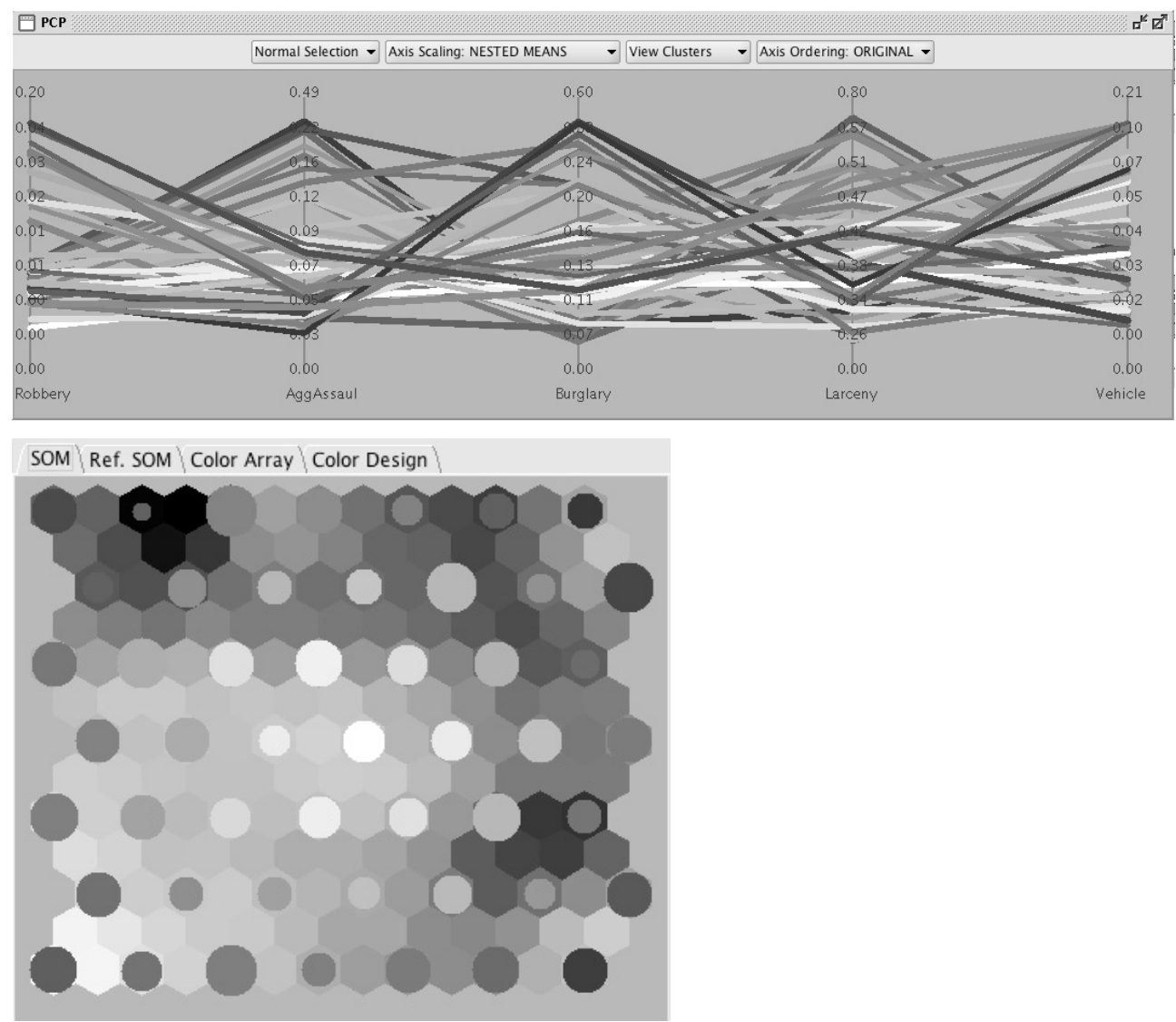

Fig. 1: Parallel coordinate plot showing clusters of similar composition of five different crime types across Louisiana parishes for the twelve months in 2005 (top). The different colors were derived from a SOM (bottom), in which the circle sizes represent the cluster sizes.

The final step in the analysis involved the creation of a space-time matrix, in which the rows (i.e., parishes) are re-ordered according to their similarities to each other so that parishes with similar temporal trends on selected crime types are next to each other in the matrix (figure 3). The matrix shows clusters of similar composition of five different crime types across all 64 Louisiana parishes for each of the twelve months in 2005. The different colors were derived from a SOM (figure 1 bottom) with the meaning of each color shown in the parallel coordinate plot (figure 1 top). 


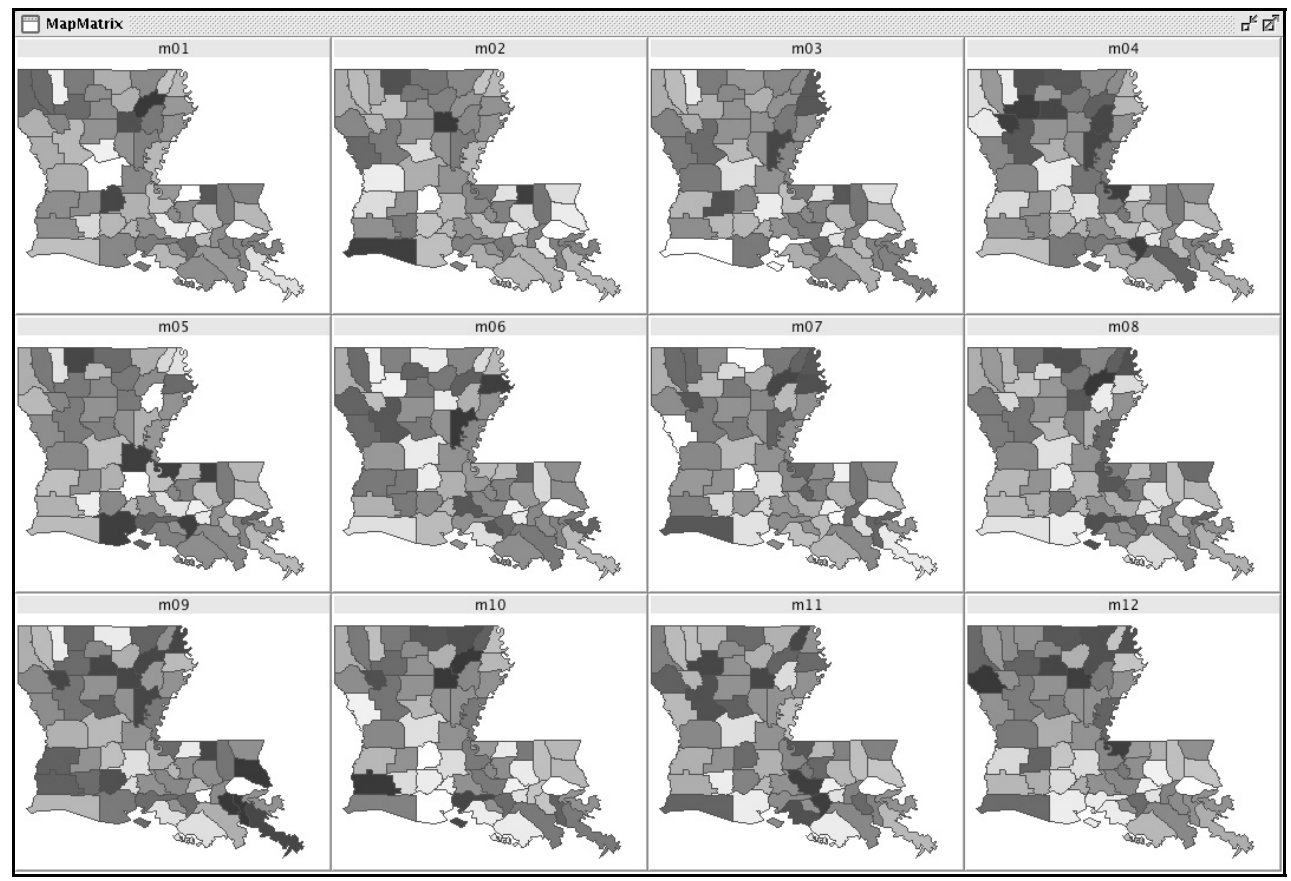

Fig. 2: Crime compositions for each month and parish in 2005 of five crime types shown in different colors derived from a SOM

One interesting feature that is readily apparent in the maps (figure 2) is that in the month immediately following Hurricane Katrina (September 2005), reddish colors surged in the state of Louisiana. We can clearly see that reddish colors are much more prominent in the September map than in any other map. In particular, the month of September is the only time when Orleans Parish is filled with a red color. After September the reddish color dissipates again. The parallel coordinate plot reveals that the reddish colors constitute a crime composition with high percentages of burglary crimes and rather low percentages of larceny crimes and robberies. In this plot each line (string) is a cluster of a similar composition of crimes, with similar clusters being visualized with similar colors. As such, reddish clusters indicate that in a place and time burglary crime percentage is relatively high (comparing to its overall average). In the space-time matrix view (figure 3), we can also see a similar pattern, where a group of parishes with a block of red colors in September (m09) are grouped together in the matrix, indicating that these parishes experienced a high rate of burglary (as interpreted from the PCP) in September in 2005. In the m09 map in the map matrix (figure 2), we can see where these three parishes are. The red color of this group of parishes that emerges in September gradually dissipates in October. 


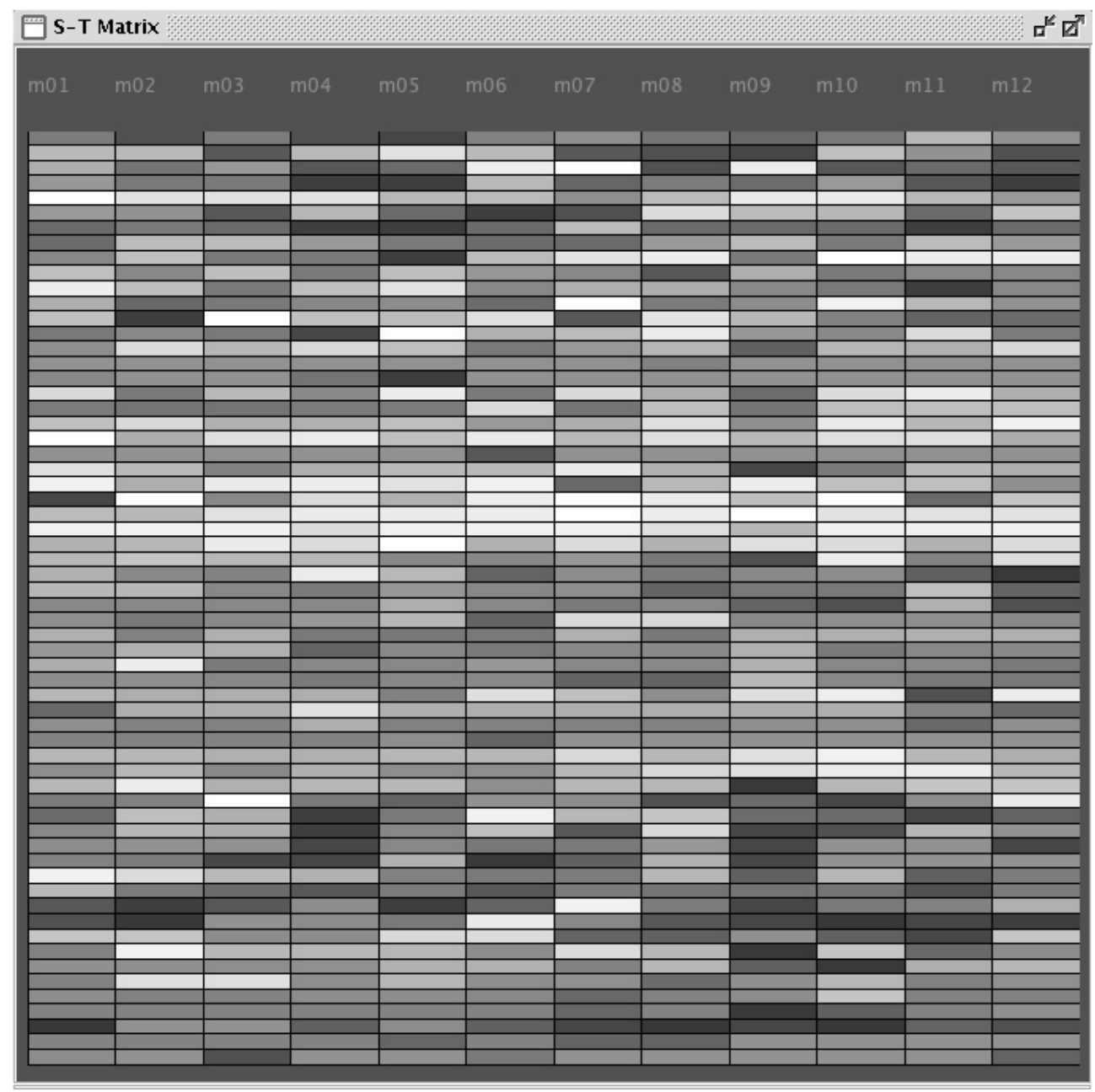

Fig. 3: Space-time matrix

\section{Conclusion and Discussion}

This study is a first exploratory analysis applying the visual analytics approach to evaluate the effect that one specific natural disaster, hurricanes, has on crime in all 64 parishes of Louisiana. The dataset analyzed included eight individual crime types for all 64 parishes for 2005, aggregated by month. The specific visual analytics approach used was VIS-STAMP that can be used to analyze datasets containing geographic locations, time series, and multiple variables (GUO et al. 2006). To the best knowledge of the authors, this is the first time that such a visual analytics approach was used to answer this particular research question. 
One interesting result of this study is that in the month immediately following Hurricane Katrina (September 2005), burglaries surged in the state of Louisiana. After September burglaries became less prominent and dissipated again. This one month increase in burglaries coincides with rather low percentages of larceny crimes and robberies. The surge in burglary crimes in Louisiana in September 2005 somewhat parallels the findings by LEITNER and HELBICH (2011), who found a significant short-term increase in burglaries and auto thefts in Houston, TX. Their study identified a large, highly significant spatio-temporal burglary cluster located in the northeastern part of Houston, which lasted from a few days before to a few days after the landfall of Hurricane Rita. In addition, empirical evidence was found that the mandatory evacuation order that was issued prior to the arrival of Hurricane Rita led to a short-time spike in burglaries. It was assumed that these crimes were committed by individuals who did not follow the evacuation order, but instead burglarized the residences of individuals who did evacuate. No mandatory evacuation order was issued for Hurricane Katrina, hence no spike in burglaries and auto thefts was detected in any parts of Houston shortly before or after Hurricane Katrina made landfall.

The results from this preliminary analysis are promising, but more research needs to be conducted before an informed decision can be made whether the visual analytics approach can add significantly new knowledge to the state-of-the-art crime analysis. As of this writing the authors are preparing further analysis using monthly crime data not only for 2005 but for the time-period from 2000-2010 for the same eight crime types and 64 Louisiana parishes. Whatever the outcome, the results from this and similar research are important for law enforcement, politicians, city planners, and disaster managers to learn from the past and better prepare for future disasters.

\section{References}

Agnew, R. (2005), Why Do Criminals Offend? A General Theory of Crime and Delinquency. Los Angeles, Roxbury.

ANDRESEN, M. A. \& TONG W. (2012), The Impact of the 2010 Winter Olympic Games on Crime in Vancouver. Canadian Journal of Criminology and Criminal Justice, 54 (3), 333-361.

BAILEY, K. L. (2009), An Evaluation of the Impact of Hurricane Katrina on Crime in New Orleans, Louisiana. Unpublished Applied Research Project for a Masters of Public Administration, Department of Political Science, Texas State University, San Marcos, TX.

Cohen, L. E. \& Felson, M. (1979), Social Change and Crime Rate Trends: A Routine Activities Approach. American Sociological Review, 44, 588-608.

Cromwell, P., Dunham, R., Akers, R. \& Lanza-Kaduce, L. (1995), Routine Activities and Social Control in the Aftermath of a Natural Catastrophe. European Journal of Criminal Policy and Research, 3 (3), 56-69.

DrabeK, T. E. \& MCEnTIRE, D. (2003), Emergent Phenomena and the Sociology of Disaster: Lessons, Trends and Opportunities from the Research Literature. Disaster Prevention and Management: An International Journal, 12 (2), 97-112.

FEDERAL BUREAU OF INVESTigation (2007), Uniform Crime Reporting Program. Washington, DC: Federal Bureau of Investigation, http://www.fbi.gov/ucr/ucr.htm (20 April 2013). 
Frailing, K. \& HARPER, D. W. (2007), Crime and Hurricanes in New Orleans. In: Brunsma, D. L., Overfelt, D. \& Picou, J. S. (Eds.), The Sociology of Katrina: Perspectives on a Modern Catastrophe. Lanham, MD, Rowman \& Littlefield, 51-68.

GuO, D. \& WU, J. (2013), Understanding Spatiotemporal Patterns of Multiple Crime Types with a Geovisual Analytics Approach. In: LeITNER M. (Ed.), Crime Modeling and Mapping Using Geospatial Technologies. New York, Springer, 367-385.

GUO, D., Chen, J., MacEAchren, A. \& LiaO, K. (2006), A Visualization System for Space-Time and Multivariate Patterns (VIS-STAMP). Journal IEEE Transactions on Visualization and Computer Graphic, 12 (6), 1461-1474.

Lanza-Kaduce, L., Dunham, R., Akers, R. L. \& Cromwell, P. (1998), Policing in the Wake of Hurricane Andrew - Comparing Citizens' and Police Priorities. Policing: An International Journal of Police Strategies \& Management, 21 (2), 330-338.

Lawton, B. A. \& SchulenburG, J. (2007), Assessing the Impact of Hurricane Katrina on Space-Time Clusters of Crime Patterns in Houston. In: Proceedings of the Ninth Crime Mapping Research Conference, Pittsburgh, PA.

LeBeAU, J. L. (2002), The Impact of a Hurricane on Routine Activities and on Calls for Police Service: Charlotte, North Carolina, and Hurricane Hugo. Crime Prevention and Community Safety: An International Journal, 53-64.

Leitner, M. \& HelBiCh, M. (2011), The Impact of Hurricanes on Crime: A SpatioTemporal Analysis in the City of Houston. TX. Cartography and Geographic Information Science, 38 (2), 214-222.

Leitner, M., BARnetT, M., Kent, J. \& BARnett, T. (2011), The Impact of Hurricane Katrina on Reported Crimes in Louisiana: A Spatial and Temporal Analysis. The Professional Geographer, 63 (2), 244-261.

LOUISIANA COMMISSION ON LAW ENFORCEMENT (2007), Louisiana Uniform Crime Reporting Program. Baton Rouge: LCLE. http://www.lcle.state.la.us/programs/laucr.asp (20 April 2013).

MunASINGHE, M. (2007), The Importance of Social Capital: Comparing the Impacts of the 2004 Asian Tsunami on Sri Lanka, and Hurricane Katrina 2005 on New Orleans. Ecological Economics, 64 (1), 9-11.

O'Grady, P. (2011), Super Bowl's Economic Impact Varies by Site. Phoenix Business Journal, October 11 2011. http://www.bizjournals.com/phoenix/news/2011/10/11/superbowls-economic-impact-varies-by.html (April 20 2013).

SAMPSON, R. J. \& GRoves, W. B. (1989), Community Structure and Crime: Testing Social Disorganization Theory. American Journal of Sociology, 94, 774-802.

SUAR, D. \& KAR, S. (2005), Social and Behavioral Consequences of the Orissa Supercyclone. Journal of Health Management, 7 (2), 263-74.

VAnLANDingham, M. J. (2007), Murder Rates in New Orleans, LA, 2004-2006. American Journal of Public Health, 97 (9), 1614-1616.

VAnLAndingham, M. J. (2008), 2007 Murder Rates in New Orleans, Louisiana. American Journal of Public Health, 98 (5), 776-777.

WENGER, D. \& Friedman, B. (1986), Local and National Media Coverage of Disaster: A Content Analysis of the Printmedia's Treatment of Disaster Myths. International Journal of Mass Emergencies and Disasters, 4 (3), 27-50. 